Gut, 1960, 1, 321.

\title{
A CASE OF SPONTANEOUS RUPTURE OF THE NORMAL LARGE BOWEL CAUSING HAEMOPERITONEUM
}

\author{
BY
}

C. T. HOWE

From Hillingdon Hospital, Uxbridge

A case of spontaneous partial rupture of the normal large bowel causing a haemoperitoneum is described. No similar case appears to have been reported previously.

Spontaneous rupture of the normal large bowel is a rare condition. In a recent article Cronin (1959) described two cases and reviewed a further 10 cases from the literature. In all 12 cases the rupture of the bowel was complete, with associated faecal soiling of the peritoneum. In the present case the rupture was partial, only the serous and muscular layers being involved.

\section{CASE History}

C.C., a man aged 59, a panel-beater, was admitted to hospital on September 1, 1959. While at work that morning he developed severe abdominal pain, at first colicky and generalized but later localized, persistent and sharp in the lower abdomen. Shortly after the onset he took a purgative which made the pain so severe that he fainted. He did not vomit but had no appetite and later felt persistently nauseated. He had had a normal bowel action earlier that day and had a further action after the dose of purgative.

Examination showed a man fit for his age, comfortable while lying still but with severe abdominal pain on movement. His temperature was $100 \cdot 4^{\circ} \mathrm{F}$., pulse rate 88 /minute, respiration rate 20 /minute, and blood pressure was $130 / 70 \mathrm{~mm}$. Hg. There was marked foetor oris but the tongue was clean. No abnormality was found in the cardiovascular, respiratory, or central nervous systems. On abdominal examination there was marked guarding, tenderness and release tenderness over the right lower quadrant, and mild tenderness over the left hypochondrium. Liver dullness was present; bowel sounds were absent. No evidence of a hernia was found. Rectal examination showed some tenderness high up on the right. A diagnosis of acute appendicitis was made and the patient was operated on the same day, 18 hours after the onset of pain.

The abdomen was opened through a gridiron incision in the right iliac fossa. On opening the peritoneal cavity a large amount of blood was found and the appendix was normal. A right paramedian incision was then made and approximately $20 \mathrm{oz}$. of blood and clot removed from the peritoneal cavity. Most of the clot lay in the pelvis and was attached to the distal part of the sigmoid colon. When the clot was removed a longitudinal linear tear of the sero-muscular layers of the colon was revealed approximately 3 in. long; it affected the anterior taenia coli as it broadened out just above the rectosigmoid junction. Through this tear pouted colonic mucosa which appeared intact but was of a dark greyish colour. Apart from this tear no abnormality of the bowel wall was visible and there was no induration or inflammatory reaction. The edges of the torn seromuscular layers were bleeding briskly. The cut edges of the tear were brought together with continuous fine chromic catgut and then oversewn. A transverse colostomy was fashioned and brought out through the upper end of the paramedian incision, which was closed with a drain to the pelvis.

Recovery was uneventful and later sigmoidoscopy and barium enema examination showed no abnormality of the bowel. Two months later the patient was re-admitted to hospital and the colostomy closed. Since that time he has remained well. Further enquiry after his first operation revealed that in infancy he had had a rectal prolapse and since that early age he had regularly taken large doses of purgative to ensure a daily bowel action. On first getting up he spent an hour on the w.c. each day, to ensure that defaecation was satisfactory. He denied the introduction of a foreign body or the selfadministration of enemata.

\section{COMMENT}

In the previously reported cases of spontaneous rupture of the large bowel, the bowel wall has been perforated. Various factors have been incriminated, for example, raised intraabdominal pressure due to straining or sudden stress, early diverticulosis with weakening of the muscular wall of the colon, stercoral ulceration due to impacted faeces, or the presence of an external hernia. 
In four cases (Eadie, 1955; Hahn, 1931; Huntley, 1919; Weinstein and Roberts, 1952) the pain started while the patient was straining to defaecate. Of Henderson's (1957) two cases, one had had an enema shortly before laparotomy was carried out and the second had taken a purgative after the onset of abdominal pain. In one of the cases described by Cronin (1959), the precipitating factor was apparently a sudden rise in intraabdominal pressure due to a sneeze, but in the second no obvious cause could be found. This lack of obvious cause was also true of the two cases described by Brown (1944) and by Lataix (1949), although in the latter's case the presence of a large incisional hernia might have been a factor.

The probable cause of bowel rupture in the present patient was a rise in intraluminal pressure from overvigorous contraction of the muscle due to purgatives. It is not easy to dismiss as irrelevant his curious obsessive habits about his bowel movement. There was no weakness or thinning of the muscular wall of the bowel, which was of adequate thickness to be sutured safely and subsequent radiographs showed no evidence of diverticulosis. There was no stercoral ulcer, as the mucosa was intact, nor was an external hernia found at the time or subsequently.

I would like to thank Mr. C. G. Scorer, under whose care this patient was admitted, for his encouragement and permission to publish this case. I am also grateful to Mr. D. H. Patey and Mr. L. P. Le Quesne for their advice and help.

\section{REFERENCES}

Brown, J. (1944). Spontaneous perforation of the pelvic colon. Brit. J. Surg., 31, 307-8.

Cronin, K. (1959). The problem of spontaneous rupture of the normal alimentary canal. Ibid., 47, 43-50.

Eadie, J. W. (1955). Spontaneous perforation of the normal pelvic colon. Ibid., 43, 189-191.

Hahn (1931). Spontanruptur des Colon sigmoideum. (Quoted by Eadie). Zbl. Chir., 58, 469.

Henderson, R. G. (1957). Spontaneous perforation of pelvic colon. Ibid., 44, 383-5.

Huntley, E. (1919). Rupture of large intestine: Operation: Death. Brit. med. J., 2, 559-560.

Lataix, P. (1949). Deux cas de perforation spontance du colon sigmoide en péritoine libre. (Quoted by Eadie.). Sem. Hôp. Paris, 25, 2279-2281.

Weinstein, M., and Roberts, M. (1952). Spontaneous perforation of colon in absence of pathological condition. J. Amer. med. Ass., 149, 1016-7. 